\title{
Short birth interval in Ghana: Maternal socioeconomic predictors and child survival
}

\author{
Abdul R. Alhassan ${ }^{1}$, John N. Anyinzaam-Adolipore' ${ }^{2}$ Kasim Abdulai ${ }^{3}$
}

\section{AFFILIATION}

1 Department of Surgery, Tamale Teaching Hospital, Tamale, Ghana 2 Department of supervision/inspectorate unit, Ghana education service, Accra, Ghana

3 Department of Nutrition and Dietetics, School of Allied Health Sciences, University of Cape Coast, Cape Coast, Ghana

CORRESPONDENCE TO

Abdul R. Alhassan. Department of Surgery, Tamale Teaching Hospital, P.
0. Box TL16, Tamale, Ghana. E-mail: Alhassana84@yahoo.com ORCID ID: https://orcid.org/0000-0003-2252-2646

\section{KEYWORDS}

Ghana, spacing, socioeconomic, predictors, small, birth

Received: 11 November 2021, Revised: 16 January 2022 Accepted: 17 January 2022

\begin{abstract}
INTRODUCTION Short birth interval is a problem in second and third world countries, where statistics show that about $17 \%$ of women in marriage and reproductive age have unmet family planning needs. The aim of the study was to identify the socioeconomic factors that predict short birth spacing among married women in Ghana.

METHODS This study was an analytic cross-sectional study relying on secondary data analysis from cross-sectional Ghana Multiple Indicator Cluster Survey (MICS) 2017-2018. The analysis was done using SPSS version 20 (IBM Corp., 2011, and NY). Bivariate analysis was done using chi-squared and predictor variables identified using binary logistic regression. The level of significance was set at $\mathrm{p}<0.05$.

RESULTS The study's prevalence of short birth intervals was $49.7 \%$. Child survival was $44 \%$ less likely in children with a
\end{abstract}

short birth interval than those without a short birth interval $(\mathrm{OR}=0.56$; 95\% CI: 0.51-0.62). Factors with significant relationships with the birth interval at the two variable analysis stage were further modelled with a binary logistic regression model in multiple variables analysis to identify predictors of short birth interval. The sociodemographic factors that predicted short birth intervals included lower maternal age, high education level, rural, from central region, having no health insurance, Mole Dagbani tribe, poorest wealth index, and high parity position $(\mathrm{p}<0.05)$.

CONCLUSIONS This study recorded a high prevalence of short birth intervals. Predictors of short birth interval included: lower maternal age and high parity position of the current birth. Child survival was less likely for babies from a short birth interval.

\section{INTRODUCTION}

It is estimated that each year about 2 million deaths of children aged $<5$ years out of 11 million deaths can be avoided by preventing birth intervals less than 24 months ${ }^{1}$. A short birth interval is a problem in second and third world countries, where $17 \%$ of women in marriage and of reproductive age have unmet family planning needs ${ }^{2}$. More than one-third (36\%) of inter-pregnancy pregnancies happen earlier than 24 months in Ghana, and women's unmet family planning need before 23 months post-birth is $77 \%{ }^{3}$.

Trends in the Ghana demographic and health survey (GDHS, 1993), indicate that nearly $40 \%$ of married women reported unmet family planning needs, and by 2014, the GDHS reported an unmet need of $30 \%$. Indicating the transformation within the two decades has been slower than expected ${ }^{4}$.

The World Health Organization reports that the most appropriate birth spacing between the last birth and the subsequent pregnancy is 24 months, and the interval between the previous birth and the next birth is 33 months ${ }^{5}$. Sufficient birth spacing between the last birth and next pregnancy helps the woman recover well from the last birth, either short or long birth interval can cause adverse maternal effects, neonatal, and poor child health outcomes ${ }^{6}$. A pooled study reportedthatbirth problems such as preterm, low birth weight, and small for gestational age are related to short $(<18$ months) and long (>59 months) birth intervals ${ }^{6}$. In another pooled study, there was a significant relation between birth spacing less than 24 months and infant mortality ${ }^{7}$. Also, other similar studies have indicated a relationship between short 
birth spacing and schizophrenia in offspring. In pregnancy, a study has equally indicated a significant relationship between shorter inter-pregnancy spacing and pregnancy problems such as premature membrane rupture, placenta abruption, uterine rupture, and placenta previa ${ }^{9}$. Also, preeclampsia is associated with long birth spacing ${ }^{10}$.

A published pooled study in 2012 suggested possible mechanisms for the adverse concerns of short birth spacing, and some of them are inadequate maternal nutritional status with folate depletion, poor optimization of lactation for newborn babies, insufficient cervix, infections, poor uterine healing after birth, sibling rivalry, and poor remodeling of the endometrial blood vessel. Short birth spacing can also limit the chances for women's economic growth and their relations ${ }^{11,12}$.

Many studies have examined birth spacing effects for the mother and baby ${ }^{10-12}$. However, little is known about the socioeconomic determinants of short birth interval, especially in Ghana. Knowledge of the factors associated with short birth spacing is important to help address the problem in Ghana and other developing countries, hence this study aimed to identify socioeconomic factors that predict small birth spacing among married women in Ghana.

\section{METHODS}

This study was a secondary data analysis of the crosssectional Ghana Multiple Indicator Cluster Survey (MICS) 2017-2018. The Ghana Statistical Service conducted this survey from October 2017 to January 2018 in collaboration with the Ministry of Health, Ministry of Education, Ministry of Sanitation and Water Resources, Ministry of Gender, Children and Social Protection, Ghana Health Service, and the Ghana Education Service, as part of the Global MICS Program. Technical support was provided by the United Nations Children's Fund (UNICEF), with government funding and financial support of UNICEF, KOICA, UNDP, USAID, and the World Bank through the Statistics for Results Facility Catalytic Fund (SRF-CF).

The sampling frame assumed was from the Ghana 2010 Population and Housing Census (PHC). This encompassed all women (34595) aged 15-49 years with a history of childbirth who were permanent occupants of selected households or visitors who stayed in households chosen the night before the survey. Only women (24838) with two or more birth histories were further used for birth interval analysis.

\section{Ethical considerations}

The MICS team of UNICEF approved the protocol for using the Ghana Multiple Indicator Cluster Survey 2017-2018 dataset for this study. Institutions in charge of ordering, funding, or supervising the surveys were held accountable for ethical procedures. Each participant provided verbal agreement, and adolescents aged 15-17 years were interviewed individually after adult approval was obtained in advance from their parents or caregivers. All participants were informed that their participation was entirely optional and that their data would be kept confidential and anonymous. Respondents were also told that they could refuse to answer any or all of the questions, and that they could end the interview at any time.

\section{Study variables}

Dependent variables

The primary outcome variables of this study were small or short birth intervals and child survival. A short birth interval was considered when the gap between current and previous birth was less than two years. With child survival, children of last birth at the time of the survey were considered alive or dead for child survival.

\section{Independent variables}

The study's independent variables were the socioeconomic characteristics, demographic characteristics, and household well status.

\section{Statistical analysis}

Statistical analysis was accomplished using SPSS version 20 (IBM Corp., 2011, and NY). Categorical variables results are presented using frequencies and percentages. The birth interval was classified as a small interval when the time duration of the current birth date from the previous birth date was less than two years. The association between dependent and independent variables was done using chisquared tests. A binary logistic regression model was used to identify predictor variables of short birth intervals. Statistical significance was set at $\mathrm{p}<0.05$.

\section{RESULTS}

\section{Respondents' socioeconomic factors}

Most (69.8\%) of the mothers were aged 20-34 years, and pre-primary or none was dominant $(40.3 \%)$ in terms of the mother's educational level. About $60.3 \%$ were from rural areas. Even though most (53.4\%) of the respondents had health insurance, the majority (30.5\%) were the poorest in terms of the wealth index quintile (Table 1).

\section{Factors associated with birth interval}

The prevalence of short birth intervals in the study was $49.7 \%$. Chi-squared analysis revealed a significant relationship between birth interval and mother's age, mother's educational level, area of residence, region, and household ethnicity(Table 2). Other associated socioeconomic factors were the health insurance status of the mother, wealth index quintile, and childbirth order $(p<0.001)$. However, the functional difficulties level of the mother was not significantly associated with birth interval ( $>>0.541$ ) (age 18-49 years) (Table 3 ).

\section{Predictors of short birth interval}

Factors with significant relationships with the birth interval at the two variable analysis stage were further modelled in the 
Table 1. Demographic characteristics of the study participants, Ghana 2017-2018( $\mathrm{N}=34595)$

\begin{tabular}{|c|c|c|}
\hline Characteristics & $\mathbf{n}$ & $\%$ \\
\hline \multicolumn{3}{|l|}{ Mother's age at birth (years) } \\
\hline$<20$ & 6744 & 19.5 \\
\hline $20-34$ & 24164 & 69.8 \\
\hline$\geq 35$ & 3687 & 10.7 \\
\hline \multicolumn{3}{|l|}{ Mother's educational level } \\
\hline Pre-primary or none & 13929 & 40.3 \\
\hline Primary & 6975 & 20.2 \\
\hline JSS/JHS/Middle & 10432 & 30.2 \\
\hline SSS/SHS/ Secondary & 2337 & 6.8 \\
\hline Higher & 916 & 2.6 \\
\hline \multicolumn{3}{|l|}{ Area } \\
\hline Urban & 13718 & 39.7 \\
\hline Rural & 20877 & 60.3 \\
\hline \multicolumn{3}{|l|}{ Region } \\
\hline Western & 3160 & 9.1 \\
\hline Central & 3072 & 8.9 \\
\hline Greater Accra & 3099 & 9.0 \\
\hline Volta & 3002 & 8.7 \\
\hline Eastern & 3455 & 10.0 \\
\hline Ashanti & 4433 & 12.8 \\
\hline Brong Ahafo & 3252 & 9.4 \\
\hline Northern & 4569 & 13.2 \\
\hline Upper East & 2928 & 8.5 \\
\hline Upper West & 3625 & 10.5 \\
\hline \multicolumn{3}{|l|}{ Household ethnicity } \\
\hline Akan & 12257 & 35.5 \\
\hline GA/Damgme & 2357 & 6.8 \\
\hline Ewe & 3769 & 10.9 \\
\hline Guan & 1315 & 3.8 \\
\hline Gruma & 1721 & 5.0 \\
\hline Mole Dagbani & 8625 & 24.9 \\
\hline Grusi & 1542 & 4.5 \\
\hline Mande & 164 & 0.5 \\
\hline Other & 2823 & 8.2 \\
\hline \multicolumn{3}{|c|}{ Functional difficulties (age $18-49$ years) } \\
\hline Has functional difficulty & 4075 & 11.8 \\
\hline Has no functional difficulty & 30416 & 88.2 \\
\hline \multicolumn{3}{|l|}{ Health insurance } \\
\hline Yes & 18460 & 53.4 \\
\hline No & 16135 & 46.6 \\
\hline \multicolumn{3}{|l|}{ Wealth index quintile } \\
\hline Poorest & 10566 & 30.5 \\
\hline
\end{tabular}

Table 1. Continued

\begin{tabular}{|c|c|c|}
\hline Characteristics & $\mathbf{n}$ & $\%$ \\
\hline Second & 6894 & 19.9 \\
\hline Middle & 6307 & 18.2 \\
\hline Fourth & 5715 & 16.5 \\
\hline Richest & 5113 & 14.8 \\
\hline \multicolumn{3}{|l|}{ Birth order } \\
\hline 1 & 9614 & 27.8 \\
\hline $2-3$ & 13563 & 39.2 \\
\hline $4-6$ & 9296 & 26.9 \\
\hline$\geq 7$ & 2122 & 6.1 \\
\hline
\end{tabular}

Frequency distribution test was done. Source: MICS field survey (2018).

binary logistic regression model to identify the predictors of short birth interval. Maternal age $>20$ years protected against short birth interval, $20-34$ years (AOR $=0.27$; 95\% CI:0.240.31 ), $\geq 35$ years (AOR=0.10; 95\% CI:0.85-0.133), another protective predictor variable was maternal educational level, JSS/JHS/Middle educational level was protective against short birth interval (AOR $=0.88 ; 95 \% \mathrm{CI}$ : 0.82-0.95), but higher maternal education associated with short birth interval (AOR=1.52; 95\% CI: 1.24-1.86). Those in rural areas were more likely to report a short birth interval than those in urban areas (AOR=1.13; 95\% CI: 1.05-1.21) (Table 4).

When it comes to regional prediction, using the Western region as the reference, those from the Central region were $14 \%$ more likely to report a short birth interval $(\mathrm{AOR}=1.14$; 95\% CI: 1.01-1.29), but those in Upper East Region of the north less likely (AOR $=0.64 ; 95 \% \mathrm{CI}$ : 0.55-0.75). Also, comparing Akan to other ethnic groups, women of Mole Dagbani were 18\% more likely to report small birth spacing (AOR=1.18; 95\% CI: 1.02-1.38). Grusi women were 21\% less likely to engage in short birth interval (AOR $=0.79 ; 95 \% \mathrm{CI}$ : $0.71-0.88)$. Women of the Mende tribe were also $15 \%$ less to engage in short birth interval (AOR $=0.85 ; 95 \% \mathrm{CI}$ : $0.73-$ 0.99). Mothers without health insurance were $10 \%$ more likely to engage in short birth interval compared to those with insurance (AOR=1.10; 95\% CI: 1.05-1.16). Increased in wealth status predicted short birth interval among women using poorest wealth status as reference; second (AOR $=0.87 ; 95 \% \mathrm{CI}: 0.80-0.94)$, third (AOR $=0.78 ; 95 \%$, CI: $0.72-0.85$ ), fourth (AOR $=0.76$; 95\% CI: 0.69-0.84) and richest (AOR $=0.67 ; 95 \%$ CI: 0.60-0.76). Finally, birth order of a child, using order of 2-3 as the reference: those with a childbirth order of 4 and above were more likely to report short birth interval, 4-6 (AOR=1.3; 95\% CI: 1.22-1.37) and $\geq 7$ (AOR=2.40; 95\% CI: 2.14-2.68). The logistic regression model appropriately explained the outcome variable (short birth interval) since the Hosmer-Lemeshow goodness-of-fit test $p$-value was $>0.05\left[\chi^{2}(8)=13.610, p=0.093\right]$, hence the model fits the study data (Table 4). 
less likely in children with short birth intervals than those

Birth spacing and child survival

without short birth intervals (OR=0.56; 95\% CI: 0.51-0.62).

Table 2. Chi-squared analysis of the relationship between participants' demographic characteristics and birth interval, Ghana 2017-2018 ( $\mathrm{N}=24838)$

\begin{tabular}{|c|c|c|c|c|c|}
\hline \multirow[t]{2}{*}{ Variable } & \multicolumn{2}{|c|}{ Short birth interval } & \multirow[t]{2}{*}{$\chi^{2}$} & \multirow[t]{2}{*}{ df } & \multirow[t]{2}{*}{$\mathbf{p}$} \\
\hline & Yes & No & & & \\
\hline \multicolumn{6}{|c|}{ Mother's age at birth (years) } \\
\hline$<20$ & 1456 & 447 & 932.845 & 2 & 0.001 \\
\hline $20-34$ & 9670 & 9636 & & & \\
\hline$\geq 35$ & 1213 & 2416 & & & \\
\hline \multicolumn{6}{|c|}{ Mother's educational level } \\
\hline Pre-primary or none & 5607 & 5349 & 56.243 & 4 & 0.001 \\
\hline Primary & 2651 & 2464 & & & \\
\hline JSS/JHS/Middle & 3270 & 3734 & & & \\
\hline SSS/SHS/ Secondary & 571 & 702 & & & \\
\hline Higher & 239 & 246 & & & \\
\hline \multicolumn{6}{|l|}{ Area } \\
\hline Urban & 4242 & 5092 & 107.087 & 1 & 0.001 \\
\hline Rural & 8097 & 7407 & & & \\
\hline \multicolumn{6}{|l|}{ Region } \\
\hline Western & 1140 & 1087 & 93.513 & 9 & 0.001 \\
\hline Central & 1181 & 1002 & & & \\
\hline Greater Accra & 961 & 1081 & & & \\
\hline Volta & 989 & 1090 & & & \\
\hline Eastern & 1262 & 1226 & & & \\
\hline Ashanti & 1617 & 1517 & & & \\
\hline Brong-Ahafo & 1153 & 1190 & & & \\
\hline Northern & 1795 & 1717 & & & \\
\hline Upper East & 890 & 1250 & & & \\
\hline Upper West & 1351 & 1339 & & & \\
\hline \multicolumn{6}{|l|}{ Household ethnicity } \\
\hline Akan & 4381 & 4206 & 115.338 & 8 & 0.001 \\
\hline GA/Dangme & 793 & 829 & & & \\
\hline Ewe & 1234 & 1355 & & & \\
\hline Guan & 500 & 463 & & & \\
\hline Gruma & 790 & 539 & & & \\
\hline Mole Dagbani & 2916 & 3467 & & & \\
\hline Grusi & 543 & 591 & & & \\
\hline Mande & 66 & 56 & & & \\
\hline Other & 1107 & 985 & & & \\
\hline
\end{tabular}

Chi-squared analysis was done for association. Source: MICS field survey (2018). 
Table 3. Chi-squared analysis of the relationship between other studied factors and birth interval, Ghana 20172018(N=24838)

\begin{tabular}{|c|c|c|c|c|c|c|}
\hline \multirow[t]{2}{*}{ Variable } & & \multicolumn{2}{|c|}{ Short birth interval } & \multirow[t]{2}{*}{$\chi^{2}$} & \multirow[t]{2}{*}{ df } & \multirow[t]{2}{*}{$\mathbf{p}$} \\
\hline & & Yes & No & & & \\
\hline \multirow{2}{*}{$\begin{array}{l}\text { Functional difficulties } \\
\text { (age 18-49 years) }\end{array}$} & Has functional difficulty & 1520 & 1572 & 0.374 & 1 & 0.541 \\
\hline & Has no functional difficulty & 10816 & 10926 & & & \\
\hline \multirow[t]{2}{*}{ Health insurance } & Yes & 6094 & 6790 & 60.604 & 1 & 0.001 \\
\hline & No & 6245 & 5709 & & & \\
\hline \multirow[t]{5}{*}{ Wealth index quintile } & Poorest & 4293 & 3752 & 133.084 & 4 & 0.001 \\
\hline & Second & 2662 & 2456 & & & \\
\hline & Middle & 2149 & 2326 & & & \\
\hline & Fourth & 1832 & 2109 & & & \\
\hline & Richest & 1403 & 1856 & & & \\
\hline \multirow[t]{3}{*}{ Child birth order } & $2-3$ & 6650 & 6770 & 26.060 & 2 & 0.001 \\
\hline & $4-6$ & 4526 & 4770 & & & \\
\hline & $\geq 7$ & 1163 & 959 & & & \\
\hline
\end{tabular}

Chi-squared analysis was done for association. Source: MICS field survey (2018).

Table 4. Binary logistic regression for predictors' short birth interval, Ghana 2017-2018 (N=24838)

\begin{tabular}{|c|c|c|c|c|}
\hline \multirow[t]{2}{*}{ Variable } & \multirow[t]{2}{*}{ Sig. } & \multirow[t]{2}{*}{ AOR } & \multicolumn{2}{|c|}{$95 \% \mathrm{CI}$} \\
\hline & & & Lower & Upper \\
\hline$<20$ & 0.000 & & & \\
\hline $20-34$ & 0.000 & 0.274 & 0.244 & 0.306 \\
\hline$\geq 35$ years & 0.000 & 0.098 & 0.085 & 0.113 \\
\hline Pre-primary or none & 0.000 & & & \\
\hline Primary & 0.493 & 0.974 & 0.904 & 1.050 \\
\hline JSS/JHS/Middle & 0.001 & 0.881 & 0.816 & 0.952 \\
\hline SSS/SHS/ Secondary & 0.835 & 1.014 & 0.889 & 1.156 \\
\hline Higher & 0.000 & 1.518 & 1.240 & 1.857 \\
\hline Area(rural/urban) & 0.001 & 1.126 & 1.052 & 1.206 \\
\hline Western & 0.000 & & & \\
\hline Central & 0.032 & 1.144 & 1.012 & 1.293 \\
\hline Greater Accra & 0.187 & 1.097 & 0.956 & 1.257 \\
\hline Volta & 0.172 & 0.899 & 0.771 & 1.048 \\
\hline Eastern & 0.579 & 0.966 & 0.855 & 1.092 \\
\hline Ashanti & 0.153 & 1.087 & 0.970 & 1.218 \\
\hline Brong-Ahafo & 0.103 & 0.902 & 0.796 & 1.021 \\
\hline Northern & 0.084 & 0.888 & 0.777 & 1.016 \\
\hline Upper East & 0.000 & 0.643 & 0.553 & 0.747 \\
\hline Upper West & 0.184 & 0.907 & 0.786 & 1.047 \\
\hline Akan & 0.000 & & & \\
\hline GA/Dangme & 0.633 & 1.028 & 0.918 & 1.150 \\
\hline Ewe & 0.191 & 0.906 & 0.782 & 1.050 \\
\hline Guan & 0.122 & 0.893 & 0.773 & 1.031 \\
\hline
\end{tabular}


Table 4. Continued

\begin{tabular}{|c|c|c|c|c|}
\hline \multirow[t]{2}{*}{ Variable } & \multirow[t]{2}{*}{ Sig. } & \multirow[t]{2}{*}{ AOR } & \multicolumn{2}{|c|}{$95 \%$ CI } \\
\hline & & & Lower & Upper \\
\hline Gruma & 0.618 & 1.044 & 0.882 & 1.234 \\
\hline Mole Dagbani & 0.027 & 1.184 & 1.019 & 1.375 \\
\hline Grusi & 0.000 & 0.792 & 0.710 & 0.883 \\
\hline Mande & 0.037 & 0.849 & 0.728 & 0.990 \\
\hline Other & 0.882 & 0.972 & 0.664 & 1.421 \\
\hline Health insurance(no/yes) & 0.000 & 1.104 & 1.046 & 1.164 \\
\hline Poorest & 0.000 & & & \\
\hline Second & 0.000 & 0.866 & 0.802 & 0.936 \\
\hline Middle & 0.000 & 0.782 & 0.716 & 0.854 \\
\hline Fourth & 0.000 & 0.759 & 0.687 & 0.839 \\
\hline Richest & 0.000 & 0.673 & 0.600 & 0.756 \\
\hline $2-3$ & 0.000 & & & \\
\hline $4-6$ & 0.000 & 1.288 & 1.215 & 1.365 \\
\hline$\geq 7$ & 0.000 & 2.395 & 2.141 & 2.679 \\
\hline Constant & 0.000 & 3.943 & & \\
\hline
\end{tabular}

Hosmer-Lemeshow goodness-of-fit test: $\chi^{2}(8)=13.610, p=0.093$.Short birth interval dummy coded: 0 for No and 1 for Yes. Binary logistic regression was applied for predication. The model controlled for ethnicity and region of orientation. Source: MICS field survey (2018).

\section{DISCUSSION}

More than one-third (36\%) of inter-pregnancy pregnancies happen earlier than 24 months in Ghana, and women's unmet family planning need for 23 months post-birth was $77 \%^{3}$. The prevalence of short birth intervals is higher $(49.7 \%)$ in this current study than the previously reported prevalence of $36 \%$. Meanwhile, another study in Ghana reported a short birth interval prevalence to be $80.0 \%{ }^{13}$.

In terms of child survival, the analysis further revealed that child survival is $44 \%$ less likely in children with a short birth interval. In addition, a similar study in Bangladesh, short birth interval predicted poor baby survival ${ }^{14}$. In another pooled research, there was a significant relation between birth spacing less than 24 months and infant mortality ${ }^{7}$. The clinical significance of this finding is that reducing short birth intervals can help reduce infant mortality in Ghana.

The main aim of this study was to identify maternal socioeconomic factors as predictors of short birth intervals in Ghana. Factors with significant relationships with a birth interval at the two variable analysis stage were further modelled with binary logistic regression model in multiple variables analysis to identify predictors of short birth interval.

Higher maternal age was identified as a lower risk for short birth intervals. Mothers of age 20-34 years were $73 \%$ less likely to have babies with the short birth interval than those aged $<20$ years, and those aged $>34$ years were
$90 \%$ less likely to have babies with the short birth interval compared to those aged $<20$ years. This study finding is not consistent with the results of Ngianga-Bakwin and Stones ${ }^{15}$. However, this was consistent with other similar studies ${ }^{16,17}$.

In addition, the birth order of a child predicted short birth intervals. Children in birth order 4 were more likely to experience short birth interval compared to those in birth order 2-3, and this is not in line with an earlier study in which increased parity position of a child protected against short birth interval ${ }^{14,16}$. However, in another African study, the expanded parity position of a child predicted a short birth interval ${ }^{18}$. A study reported that women of a younger age at first marriage were less likely to engage in small birth spacing for their first birth interval ${ }^{19}$.

Another protector variable was mother educational level; a mother with JSS/JHS/Middle educational level was $22 \%$ less likely to engage in the short birth interval compared to those with pre-primary or no education, and this study finding is not different when compared with other similar studies in Africa ${ }^{12,15,16}$. However, those with higher educational level were $52 \%$ more likely to engage in the short birth interval when compared with those with preprimary education or none. This is in line with a previous study that reported increased education status as protection against short birth intervals ${ }^{12,15,16}$.

A study in Uganda reported a short birth interval prevalence of $52.4 \%$ among rural women ${ }^{20}$. In this current 
study, rural women were more likely to engage in a short birth interval when compared to urban women. Also, a study in Sub-Saharan Africa by Ngianga-Bakwin and Stones ${ }^{15}$ reported that urban women were less likely to engage in the short birth interval than those in rural areas. Also, in terms of regional prediction, those from the Central region in southern Ghana were more likely to engage in the short birth interval compared to those from the Western region in south Ghana. Those in the Upper East region of northern Ghana were less likely to engage in the short birth interval than those from the Western region in southern Ghana.

Furthermore, ethnicity had a significant relation with birth interval. Women of the Mole Dagbani ethnic group were $18 \%$ more likely to engage in the short birth interval than women of the Akan ethnic group. Women of the Grusi ethnic group were $20 \%$ less likely to engage in the short birth interval than those of the Akan ethnic group, and people of the Mande tribe were less likely to engage in small birth spacing. In Ghana, the ethnic variation of the birth interval is associated with sexual taboos. For instance, some ethnic groups have a shorter delay in returning to sex after birth, while some have a long wait in resuming sexual intercourse ${ }^{21}$.

Finally, concerning economic factors, increased wealth status was a protector of the short birth interval among women. Women of second, middle, fourth, and most affluent of the wealth index quintile were less likely to engage in the short birth interval than women of the poorest quintile. The trend of analysis indicates that improvement in women's wealth index quintile leads to a decreased chance of short birth interval, and this is the same for other earlier studies in Africa ${ }^{12,15}$. Furthermore, the study revealed that women without health insurance coverage were more likely to engage in small birth spacing than women with health insurance coverage.

\section{Limitations}

This study was not without limitations; not all variables including religion, contraceptive use, duration of breastfeeding, were assessed, which, if explored, will help to shed more light on the research question. In addition, misclassification of inter-birth interval could have resulted from preterm births. Finally, recall of information can result in recall bias.

\section{CONCLUSIONS}

The prevalence of short birth intervals recorded by this study was high, and the sociodemographic factors that predicted short birth intervals included: increasing maternal age, high education level, rural residence, living in the Central region, not having health insurance, poorest wealth index, and high parity position. Finally, survival was lower for those with a small birth interval.

\section{REFERENCES}

1. Rutstein SO. Effects of preceding birth intervals on neonatal, infant and under-five years mortality and nutritional status in developing countries: evidence from the demographic and health surveys. Int J Gynaecol Obstet. 2005;89(suppl 1):S7S24. doi:10.1016/j.ijgo.2004.11.012

2. Ross JA, Winfrey WL. Contraceptive Use, Intention to Use and Unmet Need During the Extended Postpartum Period. Int Fam Plan Perspect. 2001;27(1):20-27. doi:10.2307/2673801

3. Maternal and Child Health Integrated Program, Maternal and Child Survival Program. Family Planning Needs during the First Two Years Postpartum in Ghana. MCHIP, MCSP; 2015. January 2015. Accessed January 16, 2022. https://www. mchip.net/sites/default/files/Ghana-PPFP.pdf

4. Ghana Statistical Service, Ghana Health Service, ICF International. Ghana Demographic and Health Survey 2014. GSS, GHS, ICF International; 2015. Accessed January 16, 2022. https://dhsprogram.com/pubs/pdf/fr307/fr307.pdf

5. World Health Organization. Report of a WHO Technical Consultation on Birth Spacing. World Health Organization; 2007. Accessed January 16, 2022. http://apps.who.int/iris/ bitstream/handle/10665/69855/WHO_RHR_07.1_eng. pdf?sequence $=1$

6. Conde-Agudelo A, Rosas-Bermúdez A, Kafury-Goeta AC. Birth Spacing and Risk of Adverse Perinatal Outcomes: A Meta-analysis. JAMA. 2006;295(15):1809-1823. doi:10.1001/jama.295.15.1809

7. Dadi AF. A Systematic Review and Meta-Analysis of the Effect of Short Birth Interval on Infant Mortality in Ethiopia. PLoS One. 2015;10(5):e0126759. doi:10.1371/journal.pone.0126759

8. Smits L, Pedersen C, Mortensen P, van Os J. Association between short birth intervals and schizophrenia in the offspring. Schizophr Res. 2004;70(1):49-56. doi:10.1016/j.schres.2003.10.002

9. Conde-Agudelo A, Rosas-Bermúdez A, Kafury-Goeta AC. Effects of birth spacing on maternal health: a systematic review. Am J Obstet Gynecol. 2007;196(4):297-308. doi:10.1016/j.ajog.2006.05.055

10. Cormick G, Betrán AP, Ciapponi A, Hall DR, Hofmeyr GJ; calcium and Pre-eclampsia Study Group. Inter-pregnancy interval and risk of recurrent pre-eclampsia: systematic review and meta-analysis. Reprod Health. 2016;13(1):83. doi:10.1186/s12978-016-0197-x

11. Conde-Agudelo A, Rosas-Bermúdez A, Castaño F, Norton MH. Effects of birth spacing on maternal, perinatal, infant, and child health: a systematic review of causal mechanisms. Stud Fam Plann. 2012;43(2):93-114. doi:10.1111/j.1728-4465.2012.00308.x

12. Hailu D, Gulte T. Determinants of Short Interbirth Interval among Reproductive Age Mothers in Arba Minch District, Ethiopia. Int J Reprod Med. 2016;2016:6072437. doi:10.1155/2016/6072437

13. Nti CA, Gadegbeku C, Dodoo SNA, Ofosu B, Akoto E, AgbiDzorkar M. Knowledge, Attitude and Practice of Birth Spacing among Ghanaian Mothers: Implications for Maternal and Child Nutritional Status. World Appl Sci J. 2014;31(11):19711978. doi:10.5829/idosi.wasj.2014.31.11.1286 
14. de Jonge HCC, Azad K, Seward N, et al. Determinants and consequences of short birth interval in rural Bangladesh: a cross-sectional study. BMC Pregnancy Childbirth. 2014;14:427. doi:10.1186/s12884-014-0427-6

15. Ngianga-Bakwin K, Stones RW. Birth intervals and injectable contraception in sub-Saharan Africa. Contraception. 2005;71(5):353-356. doi:10.1016/j.contraception.2004.10.013

16. Begna Z, Assegid S, Kassahun W, Gerbaba M. Determinants of inter birth interval among married women living in rural pastoral communities of Southern Ethiopia: a case control study. BMC Pregnancy Childbirth. 2013;13:116. doi:10.1186/1471-2393-13-116

17. Ismail TABT, Hamzah TNBT, Hassan MHM, Mahmood NMZN. Prevalence and factors associated with short birth spacing among Malay women in Kota Bharu, Kelantan, Malaysia. Int Med J. 2008;15(2):131-136.

18. Exavery A, Mrema S, Shamte A, et al. Levels and correlates of non-adherence to WHO recommended inter-birth intervals in Rufiji, Tanzania. BMC Pregnancy Childbirth. 2012;12:152. doi:10.1186/1471-2393-12-152

19. Chernet AG, Shebeshi DS, Banbeta A. Determinant of time-to-first birth interval after marriage among Ethiopian women. BMC Womens Health. 2019;19(1):157. doi:10.1186/s12905-019-0858-3

20. Aleni M, Mbalinda SN, Muhindo R. Birth Intervals and Associated Factors among Women Attending Young Child Clinic in Yumbe Hospital, Uganda. Int J Reprod Med. 2020;2020:1326596. doi:10.1155/2020/1326596

21. Benefo KD, Tsui AO, Johnson JDG. Ethnic differentials in child-spacing ideals and practices in Ghana. J Biosoc Sci. 1994;26(3):311-326. doi:10.1017/s0021932000021404

\section{CONFLICTS OF INTEREST}

The authors have completed and submitted the ICMJE Form for Disclosure of Potential Conflicts of Interest and none was reported.

\section{FUNDING}

There was no source of funding for this research.

\section{ETHICAL APPROVAL AND INFORMED CONSENT}

The study protocol for using the Ghana Multiple Indicator Cluster Survey 2017-2018 existing data was approved by the MICS team of UNICEF. Institutions in charge of ordering, funding, or supervising the surveys were held accountable for ethical procedures. All participants provided verbal informed consent.

\section{DATA AVAILABILITY}

The data supporting this research are available from the the Multiple Indicator Cluster Survey (MICS) website upon request: https://mics. unicef.org/surveys

\section{PROVENANCE AND PEER REVIEW}

Not commissioned; externally peer reviewed. 